\title{
Introducing Diagnosis-Related Groups in Kazakhstan: evolution, achievements, and challenges
}

\section{Abstract}

In 2012, Kazakhstan introduced Diagnosis-Related Groups (DRGs), as part of a package of reforms which sought to contain costs and to improve efficiency and transparency in the health system; but the main challenge was to design and implement a DRG system in just one year.

In 2011-2012, Kazakhstan developed its own DRG system. Initially 180 DRGs were defined to group inpatient cases but this number was subsequently expanded to more than 400 . Because of time limits, the cost weights had to be derived in the absence of existing standard hospital cost accounting systems, and a national patient data transfer system also needed developing. Most importantly, huge efforts were needed to develop a regulatory framework and build up DRG capabilities at a national level.

The implementation of DRGs was facilitated by strong political will for their introduction as part of a coherent package of health reforms, and consolidated efforts to build capacity. DRGs are now the key payment mechanism for hospitals. However the reforms are not fully institutionalized: the DRG structure is continuously being refined in a context of data limitations, and the revision of cost weights is most affected by insufficient data and the lack of standardized reporting mechanisms. Capacity around DRG coding is also still being developed.

Countries planning to introduce DRG systems should be aware of the challenges in moving too quickly to implement DRGs as the main hospital reimbursement mechanism.

\section{Keywords}

DRG payment; payment reforms; Kazakhstan; health care reform; hospital; inpatient care

\section{Introduction}

Kazakhstan is an upper-middle income country in Central Asia which spent $4.3 \%$ of GDP on health in $2013,53 \%$ of which was from public sources ${ }^{1}$. When Kazakhstan gained independence from the Soviet Union in 1991 it inherited an overcapacity in inpatient care with 1091 acute care hospital beds per 100000 population in 1990 . Under the Soviet system there was a strong incentive for the continuous expansion of staff and bed numbers as financing mechanisms were input-based. Since 
independence, hospital capacity has more than halved (444 acute care hospital beds per 100,000 population in 2013), but it remains well above the EU average (356 per 100,000 in 2013) ${ }^{1}$. The average length of stay is very long (9.4 days in acute care hospitals in 2013) compared with the EU average $(6.3$ in 2013 ) which potentially explains why the bed occupancy rate is so high $(86.8 \%$ in $2013,76.6 \%$ in the EU in 2012) despite the relatively low throughput of patients (14.7 acute hospital discharges per 100 in 2013, 16.2 in the EU) ${ }^{1}$.

Reforms since independence have sought to move to output-based financing mechanisms, but cost containment and ensuring adequate financing for the hospital sector have proved difficult. The current restructuring process is wide-ranging as it encompasses wholesale reform of health financing mechanisms and provider payment mechanisms to improve efficiency and equity, alongside reforms to the health care delivery system to strengthen primary and inpatient care ${ }^{2}$. In the hospital sector two aspects of the reform programme which have had the greatest impact are the introduction of DRGs for purchasing services and the autonomization of providers. Most hospitals remain stateowned, but over the past 20 years they have been granted greater managerial autonomy, having previously been the responsibility of their respective level of government. After the radical decentralization of purchasing to the local level in 1999, there has been a gradual consolidation and defragmentation of resource pooling with regional health departments purchasing all services from 2005 to 2009. Since 2010, the purchasing of hospital services has been centralized in a single agency under the Ministry of Health (the Medical Service Purchasing Committee) ${ }^{2}$.

The introduction of a national DRG system for the reimbursement of hospitals in Kazakhstan in 2012 is an interesting example of DRG implementation, because despite facing many challenges, the new system was planned and implemented in less than a year rather than a more gradual approach over a transition period, and employed a Kazakh DRG classification and cost-weight system, rather than adapting an existing international DRG system.

The government of Kazakhstan decided to adopt DRGs as a key instrument for improving financial transparency. Grouping large numbers of similar patients enables managerial analysis and improved efficiency by incentivising hospitals through financial mechanisms to improve performance ${ }^{3,4}$. In addition, a DRG system was regarded as an important vehicle for transforming inpatient care towards a more market-driven system and as a more equitable mechanism for public resource allocation across the country to address geographical disparities. This paper adds to the growing literature in the field examining the practicalities of implementing DRGs and how the challenges can be approached or mitigated ${ }^{5,6}$. 


\section{Background}

Kazakhstan first implemented a form of DRGs under a decentralized regional financing model in 2005 but then abandoned it in 2009 for an alternative nationally financed case-based system. In common with similar reforms in some other post-Soviet countries, this case-based funding system resulted in a major upward pressure on the budget ${ }^{7}$. The initial DRG system in place before this failed to elicit the expected improvements in hospital performance because there was a conflict between the incentives created by this system and the planning system which was still based on input norms as the main determinant of funding allocations. Due to rigid financing rules and procedures, purchasers were not able to purchase selectively according to performance results and hospital managers were not able to reallocate and use resources in more cost efficient ways ${ }^{2}$.

The case-based funding reform in 2009 involved the development of Medical Economic Tariffs (METs) which used normative clinical protocols, resource unit prices and standardized volumes for cases to reimburse hospitals. The MET system placed an excessive burden on the health budget, due to significant transaction costs caused by overwhelming volumes of hospital claims, together with the unintended over-treatment of patients and up-coding to higher MET rates, which are common features in the initial development of case-based payment systems ${ }^{8,9}$. The health budget was spent after 9-10 months and the Ministry of Health was obliged to approach the Ministry of Finance for additional funding.

With the new DRG system, immediate exclusive coverage of the same services and scope as the METs was deemed politically necessary as any restriction would be perceived as a step backwards. However, the existing patient classification system based on the METs was not compatible with DRG systems used internationally, so Kazakhstan decided to develop its own DRG groups. It was felt that adapting and adjusting an existing system would take longer than self-developing one and that the MET system was generating sufficient data to enable them to do it, and this is not unusual in the Central-East European context ${ }^{10}$.

The urgent need to replace the MET system resulted in an extremely ambitious timescale for DRG implementation; the policy decision to move to a national DRG system covering most inpatient hospital services was made in 2011 and the national DRG system has been in place since January 2012. Countries tend to move gradually from a DRG patient classification system to a full hospital reimbursement system over a multi-year transition period ${ }^{11}$; but circumstances in Kazakhstan meant that DRGs had to be implemented in less than a year with the capacity development and stakeholder engagement elements running in parallel. 


\section{Content of reform}

The reintroduction of DRGs was outlined in the strategy document "The State Health Care Development Program for 2011-2015 "Salamatty Kazakhstan" which sought to develop a health system capable of providing health care for all citizens and to address key health challenges in a manner that instils a sense of shared responsibility for health between the state, employers and individuals, and achieve greater efficiency in service purchasing ${ }^{12}$. Under "Salamatty Kazakhstan" the government significantly increased resources allocated to health from the national budget. Hospitals were also granted greater autonomy while purchasing was recentralized from the regional to the national level. Contracting is now conducted by the Medical Service Purchasing Committee (a central government agency) at the national level. These changes which supported the introduction of DRGs required significant capacity development in new governance and accountability structures

13. The creation of DRGs in Kazakhstan as the key payment mechanism for inpatient services under the guaranteed package of benefits, entailed the development of DRG grouping algorithm and respective costs weights, the introduction of relevant regulations to govern hospital service purchasing through DRGs, the establishment of a national DRG unit, and some capacity building initiatives for DRG coding. The aim was to improve transparency in health system financing, to improve the technical efficiency of the health system, and to contain costs through the introduction of DRGs.

DRGs are a patient classification system that groups patients into clinically meaningful and economically homogeneous groups to (i) identify which services are provided in which hospitals (that is, through patient classification, measuring hospital output, etc); and (ii) provide incentives for the efficient use of resources within hospitals ${ }^{11}$. The DRG case-mix classification system has been widely applied around the world ${ }^{14}$. Internationally, when introducing a DRG system, it is most common to use or adapt existing patient classification systems to derive between 600 and 1200 DRG groups ${ }^{15}$. In contrast, Kazakhstan developed its own DRG system, initially to determine 180 DRG groups covering most services. From 2013, the DRG logic has extended to 430 DRG groups.

The DRG groups were classified using the main diagnosis for medical illnesses from ICD9 and the main procedures for ICD10 surgical groups. Subsequent work centred on adding groups for high cost interventions and feasibility work into the development of a "Kazakh Grouper" algorithm. Initial DRG cost weights were derived from disaggregating historical expenditure data and adapting MET normative prices as there was no existing hospital standard cost accounting system in Kazakhstan. Later development work has focussed on absorption costing methodology in sample hospitals as the 
underpinning for revising cost weights. The development of hospital standard costings was also found to be a problem when introducing DRGs in other post-Socialist settings ${ }^{16-19}$.

A national web portal for a patient data transfer system was developed with regular and timely uploading of standardized patient information to the central data agency. Legal decrees governed the hospital billing and reporting process for the initial development of DRGs included basic invoicing rules, data quality and quality control which are closely monitored on an on-going basis by three state institutions. This allowed guidelines for billing, clinical coding and standardized costing to be developed. Clinical coding is basic and later development work has focussed on improving clinical coding as an essential underpinning for improvements in DRG grouping.

Kazakhstan has few exclusions from the DRG coverage, but these include: capital charges, outpatient care, rehabilitation and children's long term care, rural hospitals, TB and oncology services, teaching and research and some high technology services e.g. transplantation surgery. Currently equity of funding continues to be under threat because highly specialized service providers are skewing reimbursement towards their high-cost low-volume services, and transparency is hampered by resistance to sharing cost data and changing reporting requirements. Work to refine incentives in the system is therefore ongoing. The Ministry of Health and Social Development (as the Ministry of Health became in 2014) has decided to select pilot hospitals to standardize cost data and establish costs centres to support DRG improvement by generating evidence for revising cost-weights.

\section{Stakeholder positions}

The key stakeholder in the introduction of the new DRG system was the Ministry of Health which initiated the DRG reform in July 2012, provided oversight for it and developed the regulatory framework. Under the Ministry, the Medical Service Purchasing Committee (as the single purchaser in the system) was the main implementer of the DRG reforms. There is also a National DRG Office which is responsible for data collection and refining the DRGs in place. The National DRG Office is a division of the Republican Centre of Health Development, which is subordinated to the Ministry of Health and Social Development. By providing loans the World Bank supported technical assistance for the development and implementation of DRGs, but the key stakeholder remained the Ministry of Health and Social Development.

Figure 1 Position of stakeholders and influence at a glance

[Figure 1 around here]

Source: adapted from Geissler and Quentin $(2010)^{20}$ 
There was considerable resistance to change in some regions and reluctance by some hospital managers to share cost information or to buy into the new administrative procedures involved, despite international evidence that increasing information through DRG development helps hospital managers run their own hospitals more effectively ${ }^{21}$. Providers were resistant to the introduction of DRGs as they were generally quite comfortable with the METs, because this system obliged the Ministry to pay for every case submitted. However, there is some evidence of "early adopter" hospitals and regions successfully using the DRG system which may become role models for others. There is certainly strong government support and leadership by Ministry of Health and Social Development through the "service purchasing" and "service quality" departments and organizational development for hospital managers has been planned.

\section{Achievements and challenges}

The development and implementation of a DRG system in Kazakhstan in under one year was a significant undertaking. The DRG system now represents the main funding channel for hospitals in Kazakhstan and it is more manageable in contract terms than the previous MET system thereby overcoming many of its limitations. However, challenges remain and significant refinement is required to maximize its potential for improving equity in financing, increasing transparency in the system, and improving the efficiency of inpatient care. International evidence indicates that it will take time for these outcomes to be realized and become fully measurable. It needs to be accompanied by wider service purchasing and service delivery reforms, and further steps are also needed to make sure these reforms are institutionalized.

Table 1: Summary of achievements and challenges in the introduction of DRGs in Kazakhstan

\begin{tabular}{|c|c|}
\hline Achievements & Challenges \\
\hline $\begin{array}{l}\text { - Strong political will for implementation } \\
\text { as part of a coherent package of reforms }\end{array}$ & $\begin{array}{l}\text { - Resistance to data sharing at the } \\
\text { institutional level }\end{array}$ \\
\hline $\begin{array}{l}\text { Development of new DRG system in the } \\
\text { absence of standard cost accounting } \\
\text { system in hospitals }\end{array}$ & $\begin{array}{l}\text { Basic clinical coding with gaps in the } \\
\text { coding of secondary diagnoses, co- } \\
\text { morbidities, complications and } \\
\text { procedures }\end{array}$ \\
\hline $\begin{array}{l}\text { Development of a patient data transfer } \\
\text { system }\end{array}$ & $\begin{array}{l}\text { - Highly specialized hospitals skewing } \\
\text { reimbursement system in their favour }\end{array}$ \\
\hline $\begin{array}{l}\text { - Technical and managerial capacity } \\
\text { building at the national level to support } \\
\text { implementation of DRGs }\end{array}$ & $\begin{array}{l}\text { - Current service price based system not } \\
\text { sufficiently accurate estimate of service } \\
\text { costs }\end{array}$ \\
\hline
\end{tabular}


- Implemented as key payment mechanism for inpatient services nationwide
- Use of DRGs for purchasing only a certain proportion of inpatient services reduced impact on efficiency

Initial assessment of the new DRG system shows that among the most critical next steps will be to develop a standardized cost accounting system to measure resource consumption of clinical activities, and to refine a Kazakh DRG Grouper by adjusting the clinical logic of the case classification system. Currently, the Kazakhstan DRG system of $400+$ groups needs to be further improved to meet international standards for reliability of clinical and cost homogeneity. In 2013, it scored 39.2\% against a minimum standard of $60 \%$ using a standard $R_{2}$ test to check the reliability of the DRG system in capturing clinical and cost homogeneity. International evidence indicates that usually $500+$ groups are needed, although most use more ${ }^{15}$.

Finally, significant efforts are needed to develop the technical capacity to manage the DRG system especially at the hospital level - so that administrators have the skills to reliably collect appropriate technical data and management understand how to analyse and use these data to enhance the performance of their autonomous hospitals. Coding requires development, as there is currently insufficient coding of secondary diagnoses, co-morbidities complications and procedures. Clear and standardized coding of all these variables is an essential requirement for an effectively functioning DRG system ${ }^{15}$. There is also no standard costing system in Kazakhstan and the current service price based systems are unlikely to represent a good estimate of service "costs" ${ }^{22}$. DRGs require a functioning hospital cost accounting system, usually based on a cost centre allocation methodology 23. But capacity building is also needed at the central level. Consequently, within the Ministry of Health and Social Development, a DRG Bureau has been established which is developing the technical competencies and capacities of staff. Further plans are being developed to increase technical capacity in costing and coding at the hospital level.

\section{Conclusion}

Over the last 3 years, the Kazakhstan health system has made progress in resolving the challenges it has faced and while DRG development has not been optimal, it did address the immediate budgetary concerns caused by the previous MET system. The Ministry of Health and Social Development has built a foundation on which the Kazakh DRG system can be developed on an ongoing basis while remaining a functional and useful instrument. DRGs are now used for purchasing a large proportion of hospital services covered under the State Guaranteed Health Benefit Package. 
The main enabling factors that allowed the DRG system to be implemented in such a short period of time included strong political will for their implementation as part of a coherent package of health reforms and the large-scale investment in information technology nationally to allow data generation. But the increased budget for hospital services and recentralization of purchasing functions were also important. As changing hospital reimbursement systems radically and quickly can undermine the credibility of a DRG system, it was important to ensure the system's acceptability by underwriting the stability of the hospital incomes during the initial change period.

Overall, the Kazakhstan experience demonstrates the need to be prepared to invest heavily from the outset and accept that implementation of DRGs will take time and prove challenging. As such, when considering adopting DRGs, countries need to go in "with their eyes open". Ideally, the introduction of DRGs should be part of a wider strategy for health system strengthening, and there should be a preparatory period for the development of a regulatory framework and underpinning systems. Significant investment in technical and managerial capacity development on a national level are also necessary, to be followed by piloting and refinement prior to the system being scaled up.

\section{References}

1. WHO Europe, Health for All Database [HFA-DB], Offline Version, November 2015 edition. 2015, WHO Europe, Copenhagen.

2. Katsaga, A., et al., Kazakhstan: Health system review. Health Systems in Transition, 2012. 14(4): p. 1-154.

3. Fetter, R., et al., Case mix definition by diagnosis-related groups. Medical Care, 1980. 18(2 Suppl): p. 1-53.

4. Langenbrunner, J.C. and M.M. Wiley, Hospital payment mechanisms; theory and practice in transition countries, in Hospitals in a Changing Europe, M. McKee and J. Healey, Editors. 2002, Open University Press: Buckingham \& Philadelphia. p. 150-176.

5. Or, Z., Implementation of DRG Payment in France: Issues and recent developments. Health Policy, 2014. 117(2): p. 146-150.

6. Polyzos, N., et al., Reforming reimbursement of public hospitals in Greece during the economic crisis: Implementation of a DRG system. Health Policy, 2013. 109(1): p. 14-22.

7. Figueras, J., R. Robinson, and E. Jakubowski, Purchasing to Improve Health Systems Performance European Observatory on Health Systems and Policies Series. 2005, Buckingham \& Philadelphia: Open University Press.

8. Lave, J.R., The effect of the Medicare prospective payment system. Annual Review of Public Health, 1989. 10(1): p. 141-161.

9. Silverman, E. and J. Skinner, Medicare up-coding and hospital ownership. Jounal of Health Economics, 2004. 23(2): p. 369-389.

10. Mathauer, I. and F. Wittenbecher, Hospital payment systems based on diagnosis-related groups: experiences in low- and middle-income countries. Bulletin of the World Health Organization, 2013. 91(10): p. 746-756.

11. Geissler, A., et al., Introduction to DRGs in Europe: Common objectives across different hospital systems in Diagnosis-Related Groups in Europe: Moving towards transparency, 
efficiency and quality in hospitals, R. Busse, et al., Editors. 2011, Open University Press: Maidenhead \& New York. p. 9-22.

12. Ministry of Health and Social Development, The State Health Care Development Program for 2011-2015 "Salamatty Kazakhstan". 2010, Ministry of Health and Social Development:

Astana, Kazakhstan.

13. Chanturidze, T., et al., Building policy-making capacity in the Ministry of Health: the Kazakhstan experience. Human Resources for Health, 2015. 13: p. 4.

14. Kimberly, J., G. de Pouvourville, and T. d'Aunno, eds. The Globalization of Managerial Innovation in Health Care. 2008, Cambridge University Press: Cambridge.

15. Kobel, C., et al., DRG systems and similar patient classification systems in Europe, in Diagnosis-Related Groups in Europe: Moving towards transparency, efficiency and quality in hospitals, R. Busse, et al., Editors. 2011, Open University Press: Maidenhead \& New York. p. 37-58.

16. Czach, K., et al., Poland: The Jednorodne Grupy Pacjentów - Polish experiences with DRGs, in Diagnosis-Related Groups in Europe: Moving towards transparency, efficiency and quality in hospitals, R. Busse, et al., Editors. 2011, Open University Press: Maidenhead \& New York. p. 359-380.

17. Kacevicius, G., DRGs in Lithuania: why DRGs and how to choose from available options. 2011, National Hospital Insurance Fund: Sofia, Bulgaria.

18. Kutzin, J., et al., Innovations in resource allocation, pooling and purchasing in the Kyrgyz health care system, in Policy Research Paper: MANAS health policy analysis project. 2002, World Health Organization: Bishkek.

19. Richardson, E., Health financing, in Trends in health systems in the former Soviet countries, B. Rechel, E. Richardson, and M. McKee, Editors. 2014, World Health Organization: Copenhagen. p. 51-75.

20. Geissler, A. and W. Quentin. Prospective payment for inpatient psychiatric care. Health Policy Monitor 2010 April 2010 [cited; Available from: http://www.hpm.org/survev/de/a15/3.

21. Schuster, M., et al., Die Nutzung der Erlösdaten der „DRGs" für ein externes Benchmarking der anästhesiologischen und intensivmedizinischen Leistungserbringung [The use of diagnosis-related-groups data for external benchmarking of anesthesia and intensive care services]. Anaesthetist, 2006. 55(1): p. 26-32.

22. Tan, S.S., et al., DRGs and cost accounting: Which is driving which? , in Diagnosis-Related Groups in Europe: Moving towards transparency, efficiency and quality in hospitals, R. Busse, et al., Editors. 2011, Open University Press: Maidenhead \& New York. p. 59-74.

23. Finkler, S.A., D.M. Ward, and J.J. Baker, Essentials of Cost Accounting for Health Care Organizations. 2007, New York, NY: Aspen Publishing. 
Figure 1 Position of stakeholders and influence at a glance

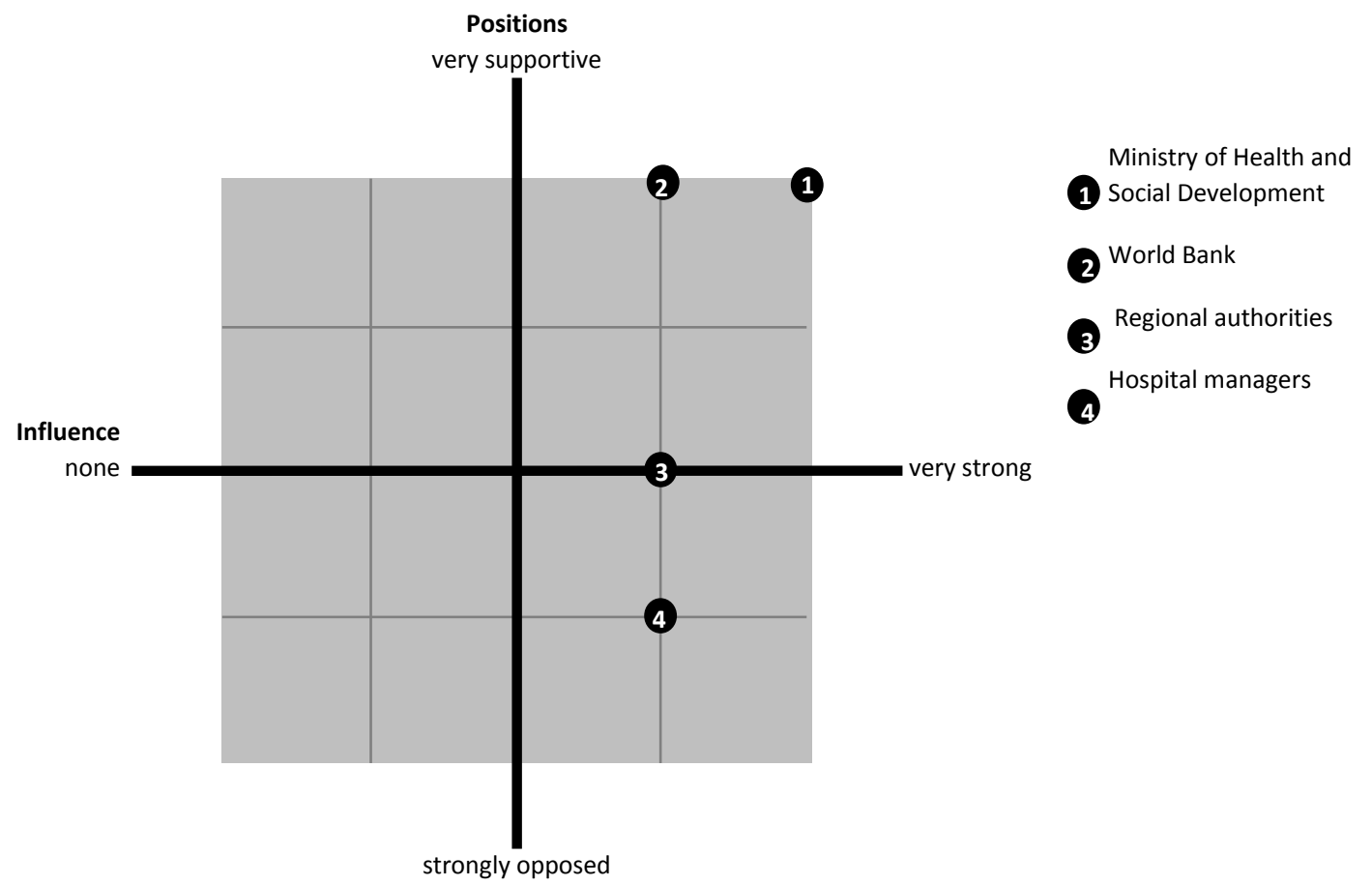

